\title{
Punção Aspirativa por Agulha Fina Orientada por Ultra-Sonografia em Lesões Não-palpáveis
}

\author{
Fine Needle Aspiration Cytology Guided by Ultrasound in Nonpalpable Lesions \\ Cláudio Kemp, Simone Elias, Karen Borrelli, Débora Garcia y Narvaiza \\ Carla G. M. Kemp, Ana Paula Schor
}

\begin{abstract}
RESUMO
Objetivo: correlacionar os achados citológicos obtidos por punção com agulha fina dirigida pela ultra-sonografia de lesões não-palpáveis da mama, císticas ou sólidas, os aspectos ultrasonográficos e os respectivos resultados histopatológicos das lesões que foram submetidas a cirurgia.

Métodos: foram analisadas 617 lesões não-palpáveis visualizadas ao ultra-som. Realizou-se a punção aspirativa por agulha fina (PAAF) orientada pela ultra-sonografia, com análise citológica do material, diferenciando-as em cistos ou nódulos sólidos. Estes tiveram seu resultado citológico confrontado com o resultado histopatológico, nos casos em que foi realizada a biópsia cirúrgica.

Resultados: das 617 lesões não-palpáveis, 471 eram cistos, sendo 451 cistos simples que apresentaram citologia negativa em todos os casos e 20 casos foram considerados cistos complexos. Destes, 3 (15\%) tiveram resultado citológico positivo ou suspeito e em 2 casos confirmou-se malignidade. Dos 105 nódulos sólidos, 63 apresentaram citologia negativa, sendo 59 concordantes com a biópsia e houve 4 casos (0,3\%) de resultado falso-negativo pela citologia. Todos, porém, apresentavam discordância entre imagem e citologia. Em 14 nódulos sólidos (13\%), a citologia foi suspeita e, destes, 5 foram diagnosticados como carcinoma. Em outros 14 (13\%), o material foi insatisfatório e 1 era carcinoma. Em 51 casos, o tríplice diagnóstico foi concordante e optou-se por seguimento clínico.

Conclusão: a análise citológica do material dos cistos mamários simples é desnecessária, porém quando são complexos, a citologia é imperativa. Nas lesões sólidas não-palpáveis, é fundamental a correlação da citologia com o aspecto ultra-sonográfico e mamográfico; caso sejam discordantes, deve-se sempre prosseguir a investigação da lesão.
\end{abstract}

PALAVRAS-CHAVE: Mama: câncer. Mama: doenças benignas. Lesões não-palpáveis. Punção por agulha fina.

\section{Introdução}

A detecção precoce do câncer de mama é fator importante na diminuição da taxa de mortalidade dessa doença e o sucesso do tratamento relaciona-se diretamente com sua instituição em fases iniciais. A mamografia é o método complementar mais específico e sensivel nessa investigação e

Setor de Patologia Mamária do LEGO São Paulo - SP (Laboratório Especializado em Ginecologia e Obstetrícia)

Correspondência:

Cláudio Kemp

Av. dos Carinás, 408

04086-010 - São Paulo - SP

Tel: (011) 5561-0610; Fax: (011) 535-6099 tem proporcionado o diagnóstico na fase pré-clinica, ou seja, o achado de lesões não-palpáveis.

As biópsias convencionais, além das inúmeras desvantagens (internação hospitalar, anestesia e suas complicações) em $80 \%$ das vezes resultam em alterações benignas, revelandose desnecessárias. Não suficiente, ainda levam a alterações do parênquima, dificultando leitura dos mamogramas subseqüentes ${ }^{1}$.

O seguimento pela imagem, apesar de constituir opção viável, não atende aos anseios psicológicos da paciente por não ser conclusivo de imediato. Também é uma conduta onerosa e dificulta a prática clínica. Entre os procedimentos 
invasivos, a punção aspirativa com agulha fina (PAAF) orientada por ultra-sonografia ou mamografia vem se mostrando método isento de complicações $^{2}$, eficiente pois a acurácia atinge cerca de $90 \%$, além de menos onerosa ${ }^{3}$.

As lesões mais comuns da mama feminina, durante a menacme, são os cistos. Ocorrem freqüentemente em mulheres com idade entre 35 e 50 anos. Cistos mamários com fluido proteináceo têm modificada sua ecogenicidade e podem ocasionar dificuldade na diferenciação com as lesões sólidas na ultra-sonografia (USG). A PAAF dirigida pela USG é o método de escolha para o diagnóstico dessas lesões. A análise citológica de rotina do conteúdo de cistos mamários tem sido preconizada por alguns autores, objetivando surpreender carcinoma intracístico. Trata-se de patologia rara e representa menos que $0,5 \%$ dos cânceres da mama. Essa conduta, no entanto, não é de consenso $^{2}$.

Quando a imagem sugere lesão sólida com características de benignidade, o diagnóstico diferencial deverá ser feito com os carcinomas circunscritos (como o medular e o mucinoso) cuja incidência varia de 5 a $7 \%{ }^{4}$.

Em ambos os casos, a complementação com a punção aspirativa torna-se imperativa e a análise citológica do material obtido objetiva confirmar o diagnóstico de benignidade ou malignidade.

Estudos da literatura, no geral, avaliam a utilidade da análise citológica do conteúdo de cistos mamários e do material proveniente dos nódulos sólidos, porém não se inclui a descrição das imagens ultra-sonográficas.

Este trabalho teve como objetivo correlacionar os achados citológicos obtidos por punção com agulha fina dirigida pela ultra-sonografia de lesões não-palpáveis da mama, císticas ou sólidas, os aspectos ultra-sonográficos e os respectivos resultados histopatológicos das lesões que foram submetidas a cirurgia.

\section{Pacientes e Métodos}

Foram avaliadas 617 lesões não-palpáveis, visibilizadas à ultra-sonografia, sendo que 471 formações eram cistos e 146 nódulos sólidos.

Considerou-se o diagnóstico realizado pelo aspecto ultra-sonográfico das lesões surpreendidas por esse exame ou como complemento de achados mamográficos, no setor de patologia mamária do Laboratório Especializado em Ginecologia e Obstetrícia. A publicação destes resultados foi aprovada pela Comissão de Ética em Pesquisa da ins- tituição.

Classificamos as lesões como cisto simples quando apresentavam as características tipicas, como forma arredondada, bem delimitada, de paredes finas, anecóica e reforço acústico posterior, e cisto complexo quando não preenchiam os critérios descritos. As lesões sólidas também foram divididas em nódulo sólido benigno, quando apresentavam forma arredondada, ovalada ou macrolobulada, limites nítidos, ecos internos homogêneos, reforço acústico posterior e sombra lateral, e nódulo sólido maligno quando apresentavam forma irregular ou microlobulada, limites imprecisos, altura maior que largura, ecos internos heterogêneos e sombra acústica posterior.

A mamografia, quando presente, foi utilizada como ferramenta no diagnóstico sendo seguida a classificação do "American College of Radiology - BI-RADS Breast Imaging Reporting and Data System". Segundo o BI-RADS, existem seis categorias de mamografias: categoria 0, que necessita complementação; categoria I que apresenta achados normais; categoria II, achados benignos; categoria III, provavelmente benignos; categoria IV, anormalidades suspeitas, e categoria V, alta suspeita de malignidade ${ }^{5}$.

Realizou-se a PAAF orientada pela USG de todas as lesões, sendo que o material obtido permitiu de imediato a diferenciação entre cistos, cistos com conteúdo espesso e nódulos sólidos.

Com uma das mãos, os examinadores posicionaram o transdutor sobre a área a examinar, orientando a visibilização do trajeto da agulha até o interior da lesão. Essa imagem permitiu a segurança de realizar o exame adequadamente.

Com o auxílio de um cabo especial (empunhadura) acoplado a uma seringa de $20 \mathrm{~mL}$ e agulha fina (25/6) conseguiu-se a mão firme para dirigir a agulha para o interior do nódulo.

No caso de cisto, o procedimento foi diagnóstico e terapêutico e, na lesão sólida, aspirou-se o material movimentando-se a agulha no interior desta, em várias direções, tomando-se o cuidado de não ultrapassá-la.

A seguir, o material obtido de todas as punções foi encaminhado para análise citológica.

O material quando líquido foi fixado em igual volume de álcool $95 \%$ e a seguir centrifugado e corado pelo método de Papanicolaou. Quando sólido, foi realizado um esfregaço sobre lâmina de microscopia, fixado em álcool $95 \%$ e corado pelo mesmo método.

Foram realizadas 617 punções, sendo que todas as lesões eram clinicamente não-palpáveis e apresentaram diâmetro igual ou inferior a 2,0 $\mathrm{cm}$. 
As lesões sólidas tiveram seu diagnóstico citológico confrontado com o resultado de biópsia cirúrgica posteriormente realizada. Trata-se de estudo retrospectivo aprovado pela comissão de ética, sendo que a coleta do material e a análise ultra-sonográfica das formações nodulares fizeram-se simultaneamente e de modo uniforme.

\section{Resultados}

As lesões foram inicialmente classificadas de acordo com o aspecto da imagem ultrasonográfica. Assim, aquelas que apresentaram aspecto cístico totalizaram 471 lesões. Destas, 451 foram classificadas como cistos simples, pois apresentavam as características descritas de cistos, e as 20 restantes sugeriam ser cistos, porém possuíam alguma peculiaridade (ecogenicidade diminuída, aspecto interno heterogêneo, etc.), sendo, então, classificadas como cistos complexos.

A Tabela 1 resume a correlação entre a imagem e o achado citológico destas lesões.

Tabela 1 - Correlação entre o aspecto da imagem ultrassonográfica (USG) e o resultado citológico de 471 cistos mamários não palpáveis.

\begin{tabular}{|c|c|c|c|c|}
\hline \multirow{2}{*}{$\begin{array}{l}\text { Aspecto da imagem USG } \\
\text { Cistos }\end{array}$} & \multicolumn{4}{|c|}{ Achado citológico } \\
\hline & M & B & $\mathbf{S}$ & I \\
\hline \multicolumn{5}{|l|}{ Simples * } \\
\hline Apócrinos & & 248 & & \\
\hline Atenuados & & & & 203 \\
\hline \multicolumn{5}{|l|}{ Complexo } \\
\hline Conteúdo espesso & & & & 10 \\
\hline Galactocele & & & & 2 \\
\hline Abscesso & & 2 & & \\
\hline Hemorrágico & & & & 1 \\
\hline nespecífico & 1 & 2 & 2 & \\
\hline Total & 1 & 252 & 2 & 216 \\
\hline
\end{tabular}

M - maligno, B - benigno, S - suspeito, I - insatisfatório

* cistos simples: atenuados = ausência de células epiteliais, apócrinos $=$ presença de células apócrinas

As seis lesões que não apresentaram concordância entre o aspecto da imagem e o resultado da citologia foram submetidas à biópsia. A citologia resultou positiva em um caso e a histologia demonstrou ser carcinoma ductal na parede do cisto. Em dois casos, a citologia foi suspeita e o exame anatomopatológico (AP) evidenciou carcinoma papilifero e adenoma papilifero. Em duas outras lesões com citologia benigna o achado histopatológico foi concordante: estroma fibrogorduroso e ginecomastia. Em apenas um caso a citologia mostrou-se insuficiente para análise, sendo que a biópsia demonstrou ser hiperplasia atípica.

Nas próximas tabelas estão resumidos os dados encontrados nas lesões sólidas. Apenas as lesões com diagnósticos posteriormente confirmados por meio de biópsia cirúrgica foram consideradas para esta análise. Assim, das 146 lesões nãopalpáveis, 105 foram biopsiadas e em 41 delas optou-se por seguimento clínico, já que a ultrasonografia e o resultado citológico foram concordantes. Esses resultados foram gentilmente cedidos pelos colegas que realizaram a cirurgia subseqüente à punção.

A Tabela 2 mostra as lesões classificadas de acordo com a citologia e o resultado AP (benigno maligno), demonstrando a sensibilidade (S), especificidade (E) e a acurácia (A), valor preditivo positivo (VP+) e valor preditivo negativo (VP-) do método no caso de lesões sólidas não-palpáveis. As citologias com resultado positivo para malignidade foram todas concordantes com o resultado AP posterior, não havendo nenhum caso falso-positivo. Já nas citologias negativas, foi confirmada a benignidade em 59 casos e em 4 casos tratava-se de falso-negativo, ou seja, AP mostrando ser carcinoma. A citologia suspeita apresentou no AP 5 casos de malignidade e 9 casos benignos e nos casos de citologia com material insuficiente havia 1 caso de neoplasia e 13 casos de achados benignos.

Tabela 2 - Correlação entre os resultados citológicos e histopatológicos das lesões sólidas não palpáveis $(n=105)$.

\begin{tabular}{lcc}
\hline Citologia & \multicolumn{2}{c}{ Histopatológico } \\
& Maligno & Benigno \\
\hline Positiva & 14 & 0 \\
Negativa & 4 & 59 \\
Suspeita & 5 & 9 \\
Material insuficiente & 1 & 13 \\
$\mathrm{n}=105$ & 24 & 81 \\
\hline Sensibilidade $=77,7 \%$ & Valor preditivo positivo $=100 \%$ & \\
Especificidade $=100 \%$ & Valor preditivo negativo $=93,6 \%$ & Acurácia $=92,4 \%$
\end{tabular}

A Tabela 3 relaciona a citologia com o achado histopatológico específico. Na maioria dos achados citológicos negativos tratava-se de fibroadenomas; nos casos com material insuficiente mostram-se nódulos que apresentam pouca celularidade, como lipomas, granuloma pós-cirúrgico, necrose gordurosa, fibrose e um caso de carcinoma. 
Tabela 3 - Correlação entre os resultados citológicos e os histopatológicos de 105 nódulos sólidos não palpáveis.

\begin{tabular}{llr}
\hline Citologia & Histopatológico & $\mathbf{n}$ \\
\hline Negativa & Fibroadenoma & 56 \\
$(\mathrm{n}=63)$ & Abscesso & 1 \\
& Alterações fibrocísticas & 1 \\
& Hamartoma & 1 \\
& Carcinoma & 4 \\
Material insuficiente & Lipoma & 8 \\
$(n=14)$ & Granuloma pós-cirúrgico & 2 \\
& Necrose gordurosa & 2 \\
& Fibrose & 1 \\
& Carcinoma & 1 \\
Suspeita & Hiperplasia atípica & 3 \\
$(n=14)$ & Alterações fibrocísticas & 3 \\
& Fibroadenoma & 2 \\
& Tumor phyllodes & 1 \\
Positiva & Carcinoma & 5 \\
\hline
\end{tabular}

Houve apenas 4 casos de citologia negativa com resultado histopatológico discordante (Tabela 4). Nesses, também o aspecto da imagem foi discordante. Em 3 casos a mamografia foi classificada como BIRADS IV, ou seja, achados suspeitos de malignidade, e houve 1 caso com mamografia BIRADS III que apresentou imagem suspeita à USG.

Tabela 4 - Correlação entre os quatro casos de achados discordantes entre citologia benigna e histopatologia maligna e os respectivos achados na mamografia e ultrasonografia (USG).

\begin{tabular}{ll}
\hline 1.Carcinoma lobular invasivo & Mamografia $=>$ BIRADS IV \\
2.Carcinoma tubular & Mamografia $=>$ BIRADS IV \\
3.Carcinoma medular & Mamografia => BIRADS III \\
& USG $=>$ suspeito \\
4.Carcinoma ductal & Mamografia => BIRADS IV \\
& USG $=>$ suspeito \\
\hline
\end{tabular}

BI-RADS = "Breast Imaging Reporting and Data System".

\section{Discussão}

\section{Cistos}

Com o advento dos exames de rastreamento, o achado de cistos mamários tornou-se muito freqüente, porém o significado clínico deste achado é ainda controverso.O estudo do fluido intracístico tem demonstrado substâncias inorgânicas, proteínas, hormônios, etc ${ }^{6}$. Este fato permitiu considerar a hipótese de esses cistos serem provenientes de transudato sangüineo ou de secreções apócrinas. O estudo do conteúdo desses cistos conduziu a classificação em dois grupos: Tipo I, em que a concentração de sódio $\left(\mathrm{Na}^{+}\right)$ excedia em muito os niveis de potássio $\left(\mathrm{K}^{+}\right)$, à semelhança do plasma, e tipo II, no qual o $\mathrm{K}^{+}$era o cátion predominante.

Na prática, observou-se que o fluido em que o $\mathrm{Na}^{+}$predominava acusava niveis baixos de sulfato de deidroepiandrosterona e IgA não-secretora, em contraste com o fluido rico em $\mathrm{K}^{+}$, em que essas substâncias apareciam em niveis elevados, sugerindo que o epitélio destes cistos apresentava alguma atividade secretora.

Também Dixon et al. ${ }^{6}$ observaram que todos os cistos nos quais a relação $\mathrm{Na} / \mathrm{K}$ era de 2 ou menos eram revestidos por epitélio apócrino, e aqueles em que a relação era de 3 ou mais eram constituídos de epitélio atenuado.

O significado clínico destes dados é que os cistos do tipo apócrino apresentam maior multiplicidade, bilateralidade e alto índice de recorrência. Também é um marcador de atipia de células epiteliais, freqüentemente associado com um maior risco de desenvolvimento de câncer.

Essa associação entre cistos apócrinos e câncer de mama foi endossada por Mazoujian et al. ${ }^{7}$, que encontraram uma alta taxa da glicoproteína GCDFP-15 (um marcador específico para epitélio apócrino) em carcinomas da mama. No entanto, outros autores não confirmaram uma associação direta entre doença fibrocística da mama tipo apócrino ou outros tipos com câncer de mama $^{8-12}$.

Rotineiramente, o exame do fluido de cistos mamários resulta em citologias benignas. Assim, também a utilidade deste procedimento tem sido questionada por muitos autores ${ }^{13}$.

Em nossos resultados, os cistos de aspecto ultra-sonográfico típico e sem outras alterações clínicas e/ou mamográficas, que apresentaram conteúdo líquido amarelo citrino, esverdeado ou marrom ( $n=451)$, revelaram $100 \%$ das citologias negativas (cistos apócrinos ou atenuados). Essa análise apenas permite, no caso dos cistos apócrinos, advertir sobre a possibilidade de recidiva e bilateralidade ${ }^{2,6}$.

Portanto, nos casos de cistos típicos à ultrasonografia, a PAAF seria indicada naqueles casos de dor localizada (na área correspondente ao cisto diagnosticado pela USG), nas lesões de crescimento rápido que causam ansiedade nas pacientes e, ainda, nos cistos de crescimento lento, porém contínuo, evidenciado em exames posteriores de con- 
trole.

Ainda, esse procedimento torna-se necessário quando ocorrem recidivas freqüentes de lesão típica no mesmo local, sugerindo epitélio de revestimento ativo, e em algumas situações especiais. Essas situações incluem: alteração da imagem (infecção ou hemorragia) dificultando o controle adequado, dor localizada, e ansiedade da paciente (cancerofobia).

Os cistos complexos, ou seja, com septos no seu interior ou com massa intracística, devem ser puncionados. Em nossa casuística, 20 cistos foram classificados como complexos e três (15\%) apresentaram resultados citológicos positivos ou suspeitos e em dois confirmou-se malignidade. Em um desses casos, a mamografia apresentava microcalcificações suspeitas (BIRADS IV) e em outro, a ultra-sonografia mostrava lesão sólida intracística. Nossos achados de 2 carcinomas intracísticos em 471 cistos $(0,4 \%)$ são comparáveis aos citados por Jackson ${ }^{14}$ de $0,6 \%$.

Convém ressaltar que a indicação da PAAF depende também de outros fatores, como o aspecto da imagem. Obviamente, é recomendado que as pacientes sejam submetidas à biópsia cirúrgica se exibirem achados suspeitos para malignidade nas mamografias e/ou ultra-sonografias, ou segundo resultado da citologia.

\section{Nódulos sólidos}

Lesões sólidas benignas tornaram-se motivo freqüente de preocupação para o clínico e para a paciente, como conseqüência dos achados em mamografias de rastreamento e também do uso cada vez mais rotineiro da ultra-sonografia mamária. Atualmente a punção aspirativa com agulha fina é um procedimento diagnóstico preciso para elucidar a natureza dos nódulos sólidos mamários, que podem ser benignos ou malignos.

Os nódulos benignos são caracterizados na sua maioria pelos fibroadenomas. Na análise citológica estes nódulos originam esfregaços bastante celulares compostos de agrupamentos arborescentes de células epiteliais dispostas em camada única, com tendência ao alongamento e presença de núcleos isolados, ovalados, normocromáticos, além de fragmentos de estroma metacromáticos. Em 70\% dos casos, este achado faz o diagnóstico de fibroadenoma ${ }^{15}$. O diagnóstico diferencial se faz com tumor filodes, que muitas vezes, pela citologia, não é distinguível do fibroadenoma ${ }^{13}$.

Em alguns casos de lesões benignas, a ausência de células epiteliais no esfregaço torna o resultado insatisfatório, como: lipoma, no qual a quantidade de células é pequena, com a presença de células adiposas; necrose gordurosa, na qual observam-se na citologia detritos celulares, raras células epiteliais e componentes inflamatórios, e nos processos inflamatórios nos quais se observam células gigantes, multinucleadas, linfócitos e células epiteliais com fenômenos degenerativos e regenerativos. Nesses casos a correlação com a clínica é que corrobora o diagnóstico.

Já os nódulos malignos, na citologia são geralmente constituídos por grande quantidade de células, com anisocariose, núcleos hipercromáticos, pleomorfismo, irregularidade na distribuição de cromatina e mitoses atípicas ${ }^{13}$. Quanto aos nódulos sólidos, a acurácia do método gira em torno de $95,7 \%{ }^{16}$.

O alto valor preditivo de malignidade $(98,7 \%)$ é de grande importância para a prática clínica. A porcentagem de resultados suspeitos, gira em torno de 0,5 a 12,4\% ${ }^{15,17-19}$. Esta variação dos resultados pode ser decorrente da inexperiência do citologista, da baixa celularidade ou da diferenciação histológica da lesão ${ }^{20}$. Os achados falso-negativos podem ocorrer em 10\% dos casos e geralmente decorrem de material insuficiente para análise, principalmente em nódulos pequenos ou lesões com alto grau de diferenciação ${ }^{16,17,21}$. Já os resultados falso-positivos são raros (em torno de $1,6 \%)^{22}$, incidindo geralmente em casos em que existe regeneração celular com aumento do volume dos núcleos e nucléolos.

Nos nossos resultados, dos 105 nódulos sólidos não-palpáveis, puncionados pela ultrasonografia, 63 casos apresentaram citologia negativa. Destes, 59 casos foram concordantes com o AP caracterizando benignidade e 4 (0,3\%) tiveram carcinoma como resultado do AP.

Em um dos 4 casos com resultado falso-negativo pela citologia, o diagnóstico não foi possivel pelo exame de congelação, tratando-se de um carcinoma tubular diagnosticado somente na parafina. Todos apresentaram discordância entre o resultado citológico e a mamografia ou aspecto ultrasonográfico, nos quais foram considerados suspeitos.

Em 14 casos o diagnóstico foi suspeito. Destes, 5 (4\%) foram diagnosticados como carcinoma pelo exame histopatológico tratando-se de tumores diferenciados, e 9 (8\%) foram diagnosticados como alterações benignas, porém com diagnóstico de lesões proliferativas, o que justifica o diagnóstico de suspeito.

Em outros 14 casos o material foi insatisfatório. Destes, somente 1 caso foi diagnosticado como carcinoma, o qual pela histologia apresentava um componente fibroso importante; os outros 13 tiveram como diagnóstico lesões que não oferecem células epiteliais para análise, o que mais uma vez justifica a baixa celularidade do 
material.

Portanto, nos casos nos quais o material é insuficiente, a citologia é suspeita, ou mesmo quando a citologia é negativa, a avaliação da mamografia e da ultra-sonografia é fundamental para se dar a conduta correta. Sempre que em nódulos não-palpáveis ocorrer discordância de um dos 3 método (citologia, mamografia ou ultrasonografia), deve-se prosseguir a investigação da lesão. Concluímos que a análise citológica do fluido de cistos mamários não-palpáveis e característicos à ultra-sonografia é desnecessária quando se objetiva surpreender o câncer da mama. Na presença de alterações ultra-sonográficas e/ou mamográficas esta análise deverá ser indicada.

Tratando-se de lesão sólida não-palpável, a punção orientada por ultra-sonografia permite a coleta adequada do material. Caso o diagnóstico imagem-citologia seja concordante, sugerindo benignidade, a conduta expectante poderá ser uma opção segura. Caso haja discordância entre citologia e ultra-sonografia ou mamografia devese sempre prosseguir a investigação.

\section{SUMMARY}

Purpose: to determine the relationship between fine needle aspiration cytology guided by ultrasound of nonpalpable breast lesions (cystic or solid masses) with the ultrasound and histopathological features of the biopsy lesions.

Methods: a total of 617 nonpalpable lesions were analyzed by ultrasound. Fine needle aspiration cytology was guided by ultrasonography and the cysts were distinguished from the solid masses by comparing the biopsies. The cytologic results were compared with the histological results in the case surgical biopsy was carried out.

Results: of the 617 nonpalpable lesions 471 were cysts (451 simple cysts with $100 \%$ negative cytology and 20 cases were considered complex cysts; 3 (15\%) of these had a positive or suspected cytology and in 2 cases malignancy was confirmed. There were 105 solid masses, 63 of them with negative cytology. Fifty-nine cases had a negative biopsy, and 4 cases $(0.3 \%)$ were false-negative but all of them presented disagreement between the cytological and image features; in 14 cases (13\%) there was a suspected cytology and in 5 of them carcinoma was confirmed; in 14 cases (13\%), the samples were insufficient, 1 case was carcinoma and in 51 cases, a triple diagnosis was concordant and the lesions were followed-up.

Conclusion: cytological analysis of simple cysts is not required, but when they are complex, cytological analysis is mandatery. In the case of nonpalpable solid masses, cytology must be correlated with ultrasound and mammography features. If the results are discordant, the lesion should be followed-up.
KEY WORDS: Breast: neoplasm. Breast: benign disease. Nonpalpable lesion. Fine needle aspiration.

\section{Referências}

1. Ciatto S, Del Turco MR, Bonardi R, et al. Nonpalpable lesions of the breast detected by mamography: review of 1182 consecutive histologically confirmed cases. Eur J Cancer 1994; 30A:40-4.

2. Hamed H, Coady A, Chaudary MA, Fentiman IS. Follow-up of patientes with aspirated breast cysts is necessary. Arch Surg 1989; 124:253-5.

3. Reynolds HE, Jackson UP. Procedimentos intervencionais orientados pela ultra-sonografia. In: Bassett LW, Jackson UP, Johan R, Fu SY, Gold RH. Doenças da Mama: diagnóstico e tratamento. $1^{\text {a }}$ ed. Rio de Janeiro: Revinter; 2000. p.263-74.

4. Rosen PP. Breast pathology. 1st ed. Philadelphia: Lippincott-Raven;1997. p.907.

5.American College of Radiology (ACR). Breast imaging reporting and data system (BI-RADS ${ }^{\mathrm{TM}}$ ). 2nd ed. Reston: American College of Radiology; 1995.

6. Dixon JM, Miller WR, Scott WN, et al. The morphological basis of human breast cyst populations. Br J Surg 1983; 70:604-6.

7. Mazoujian G, Pinkus GS, Davis S, Haagensen DE $\mathrm{Jr}$. Immunohistochemistry of a breast gross cystic disease fluid protein (GCDFP-15) of the breast. A marker of apocrine epithelium and breast carcinomas with apocrine features. Am J Pathol 1983; 110:105-12.

8. Ebbs SR, Bates T. Breast cyst type does not predict the natural history of cyst disease or breast cancer risk. Br J Surg 1988; 75:702-4.

9. Love SM, Gelman RS, Silen W. Sounding board. Fibrocystic "disease" of the breast: a nondisease? N Engl J Med 1982; 307:1010-4.

10.Dupont WD, Page DL. Risk factors for breast cancer in women with proliferative breast disease. N Engl J Med 1985; 312:146-51.

11.Page DL, Dupont WD. Are breast cysts a premalignant marker? Eur J Cancer Clin Oncol 1986; 22:635-6.

12.Devitt JE. Fibrocystic disease of the breast is not premalignant. Surg Gynecol Obstet 1972; 134: 803-6.

13. Carvalho FM. Citopatologia mamária. In: Halbe WH. Tratado de Ginecologia. $3^{a}$ ed. São Paulo: Roca; 2000. p.553-8. 
14. Jackson UP. Aspiração de cisto e pneumocistografia. In: Basset LW, Jackson UP, Johan R, Fu SY, Gold RH. Doenças da Mama: diagnóstico e tratamento. $1^{\text {a }}$ ed. Rio de Janeiro: Revinter; 2000. p.275-82.

15. Zajicek J, Franzen S, Jakobsson P, Rubio C, Ungaard B. Aspiration biopsy of mammary tumors in diagnosis and research: a critical review of 2.200 cases. Acta Cytol 1967; 11:169-75.

16. Kemp C. Punção aspirativa. In: Rodrigues de Lima G, Gebrim LH, Cintra e Oliveira V, Valente Martins N. Ginecologia Oncológica. $1^{\text {a }}$ ed. São Paulo: Atheneu; 1999. p.223-30.

17. Dixon JM, Anderson TJ, Lamb J, Nixon SJ, Forrest AP. Fine needle aspiration cytology, in relationships to clinical examination and mammography in the diagnosis of a solid breast mass. Br J Surg 1984; 71:593-6.

18. Pilotti S, Rilke.F, Delpiano C, Di Pietro S, Guzzon A. Problems in fine needle aspiration biopsy cytology of clinically or mammographically uncertain breast tumors. Tumori 1982; 68:40712.

19. Zajdela A, Ghoussein NA, Pilleron JP, Ennuyer A. The value of aspiration cytology in the diagnostic of breast cancer: experience at the Fondation Curie. Cancer 1975; 35:499-506.

20. Kreuzer G, Zajicek J. Cytologic diagnosis of mammary tumors from aspiration biopsy smears. III. Studies on 200 carcinomas with false negative or doubtful cytologic reports. Acta Cytol 1972; 16:249-52.

21. Gardecki TI, Hogbin BM, Melcher DH, Smith RS. Aspiration cytology in the preoperative management of breast cancer. Lancet 1980; 2:790-2.

22. Carvalho FM, Kemp C. Citologia mamária. In: Halbe WH. Tratado de Ginecologia. $2^{a}$ ed. São Paulo: Roca; 1994. p.443-7.

\section{XXVCONGRESSODE} GINECOLOGIAEOBSTETRÍCIA DORIODEJANEIRO

\section{5 a 18 de Agosto de 2001}

\section{Organização:SGORJ}

\section{Tel.: (0xx21) 285-0892 / 265-1525}

